\title{
Density Functional Theory and Mass Spectrometry of Phthalate Fragmentations Mechanisms: Modeling Hyperconjugated Carbocation and Radical Cation Complexes with Neutral Molecules
}

\author{
Yassin A. Jeilani, ${ }^{1}$ Beatriz H. Cardelino, ${ }^{2}$ Victor M. Ibeanusi ${ }^{1}$ \\ ${ }^{1}$ Environmental Science and Studies Program, Spelman College, 350 Spelman Lane, Box 235, Atlanta, GA 30314, USA \\ ${ }^{2}$ Department of Chemistry, Spelman College, 350 Spelman Lane, Box 238, Atlanta, GA 30314-4399, USA
}

\begin{abstract}
This is the first ab initio study of the energetics of the fragmentation mechanisms of phthalate, by mass spectrometry, leading to protonated phthalic anhydride $(\mathrm{m} / \mathrm{z}$ 149). Phthalates fragment by two major pathways; namely, the McLafferty +1 rearrangement and the loss of alkoxy. Both pathways involve a carbonyl oxygen attack to the ortho-carbonyl carbon leading to structures with tetrahedral carbon intermediates that eventually give $\mathrm{m} / \mathrm{z}$ 149. These pathways were studied by collision induced dissociation (CID) using triple quadrupole mass spectrometry. The proposed McLafferty +1 pathway proceeds through a distonic $\mathrm{M}^{*+}$, leading to the loss of an allylic-stabilized alkene radical. The McLafferty rearrangement step proceeds through a six-membered ring transition state with a small activation energy ranging $0.4-6.2 \mathrm{kcal} / \mathrm{mol}$; the transfer of a second $\mathrm{H}$ from the distonic ion of the rearrangement step proceeds through a radical cation molecule complex. Based on quantum chemical modeling of the cation molecule complexes, two kinds of cation molecule complexes were identified as radical cation molecule complex and hyperconjugated cation molecule complex. This distinction is based on the cation and simplifies future modeling of similar complexes. Optimization of important fragments in these pathways showed cyclized and hydrogen-bonded structures to be favored. An exception was the optimized structure of the protonated phthalic anhydride $(\mathrm{m} / \mathrm{z} 149)$ that showed a structure with an open anhydride ring.
\end{abstract}

Key words: Triple quadrupole mass spectrometry, Protonated phthalic anhydride, Ion molecule complexes, Phthalates, Collision induced dissociation, Hyperconjugated cation, Phthalates, Fragmentation mechanism

\section{Introduction}

$\mathrm{P}$ hthalates are high-production volume chemicals that find many applications in plastic consumer products as

Electronic supplementary material The online version of this article (doi:10.1007/s13361-011-0215-8) contains supplementary material, which is available to authorized users.

Correspondence to: Yassin A. Jeilani; e-mail: yjeilani@spelman.edu additives. They are typically used to soften and to add flexibility to plastic products. Human exposure to phthalates is possible during the production of the consumer products or during the use of such products. Since phthalates are not bound to the plastics, they can leach into the environment; and environmental phthalate exposure is possible through air, water, or food. Some studies suggested the association between phthalate exposure and adverse reproductive health outcomes [1]. Moreover, there is increasing concern of phthalates as endocrine disruptive chemicals. 
Phthalates are ubiquitous in the environment, and analytical methods for phthalates are predominantly based on mass spectrometric (MS) approaches. A variety of MS methods has been reported on phthalate mass spectrometry, including methods based on magnetic sector [2], fast atom bombardment [3], electrospray ionization [4], matrix-assisted laser desorption/ionization [5], Fourier transform ion cyclotron resonance (FTICR) [4], and both positive and negative chemical ionizations $[4,6,7]$. The fragmentation mechanisms of phthalates have been studied by both metastable ion decomposition and collision induced dissociation (CID).

It is well established that phthalate radical cations fragment in the gas phase to form protonated phthalic anhydride at $m / z 149$ [2, 6, 7]. Unfortunately, mass spectrometric evidence under electron ionization (EI) mode leading to the $\mathrm{m} / \mathrm{z} 149$ ion has been reported without a theoretical investigation of the mechanism [2]. Previous theoretical studies have provided more insight into the fragmentation mechanism of phthalates. However, these studies had focused on dimethyl phthalates that led to $\mathrm{m} / \mathrm{z}$ 163 as the dominant peak $[8,9]$.

A theoretical study of the phthalate fragmentation is currently needed to design a mechanism with correct ion structures. Insight into the ion structures and the neutral molecules involved in the mechanism is crucial for identification purposes and for calculation of the energetics of the fragmentation pathways. Phthalate fragmentations follow two distinct routes, namely, the McLafferty +1 rearrangement and the loss of alkoxy group pathways. These fragmentations are competitive; and insights into the energetics and the three dimensional ion structures with well established theoretical methods are highly desired.

In the current study, phthalate fragmentation pathways were studied by density functional theory (DFT) methods and by CID using triple quadrupole tandem mass spectrometry (MSMS) under EI conditions. The current study fills the theoretical gap to elucidate the fragmentation mechanism and to calculate the relative change of free energies of the pathways. The objective of the current study is to determine both energetics and ion structures along these pathways. Cyclic and acyclic structures were considered to determine energetically favored fragments. This approach provided a way to design a comprehensive mechanism with correct structures based on computational evidence.

\section{Experimental}

\section{Mass Spectrometry Experiments}

A Varian CP-3800 gas chromatograph was used, equipped with a VF-5 ms FactorFour (Varian, Lake Forest, CA, USA) poly(dimethylsiloxane) bonded-phase fused silica capillary column, $30 \mathrm{~m} \times 0.25 \mathrm{~mm}$ with 0.25 film thickness. Collision induced dissociation mass spectra were acquired on a Varian 320-MS TQ-Mass spectrometer. Argon was used as the collision gas (collision energies were specified in the legend for Figure 1 showing the spectra). The instrument was operated in an electron ionization (EI) mode using $70 \mathrm{eV}$ with a source and transfer line temperatures of $200{ }^{\circ} \mathrm{C}$ and $220{ }^{\circ} \mathrm{C}$, respectively. Environmental Protection Agency (EPA) method 506 phthalate standards were obtained from Supelco (Bellefonte, PA, USA). The EPA phthalates include: dibutylphthalate (DBP), benzylbutylphthalate (BBP), di-(2-ethylhexyl)-phthalate (DEHP), and di-( $n$ octyl)-phthalate (DnOP).

\section{Computational Methods}

All DFT calculations were performed on the Gaussian $03 \mathrm{~W}$ suite of programs [10]. DFT was used to determine both geometries and energetics. The B3LYP functional [11, 12] with 6-311 G(d,p) basis sets [13] was used without symmetry constraint. All optimized geometries were subjected to vibrational frequency analysis to ensure they corresponded to minima without imaginary frequency. Natural bond orbital analysis (NBO) was performed to calculate atomic charges and spin densities $[14,15]$. Zero point energies were obtained from harmonic frequency calculations without scaling. The translational, rotational, and vibrational contributions to the enthalpy and entropy were evaluated using rigid-rotor harmonic oscillation approximations. The structure of the transition states were obtained by QST2 optimization procedures at B3LYP level of theory using 6-311 G(d,p) basis sets. The transition state structures were verified by both harmonic frequency analysis and intrinsic reaction coordinate analysis $[16,17]$. The first-order saddle point for each transition state was characterized by having one imaginary vibrational frequency corresponding to the vibrational mode in the correct reaction coordinate. Optimized structures and atomic charges were visualized with GaussView 4.1 and Chemissian software packages $[18,19]$.

\section{Results and Discussion}

Analysis of phthalates has been preferably reported by mass spectrometric approaches. The $m / z 149$ is a characteristic peak used to identify phthalates; and it is observed in the EI spectra of phthalates except dimethyl phthalate (DMP). There are two major fragmentation pathways leading to $m / z 149$; namely, the McLafferty +1 and the loss of alkoxy pathways.

The CID spectra of the radical cation $\mathrm{M}^{\cdot+}$ showed both $\left[\mathrm{M}-\mathrm{CH}_{2}=\mathrm{CH}-\mathrm{CHR}\right]^{++}$and $\left[\mathrm{M}-{ }^{\circ} \mathrm{OR}\right]^{+}$with structures assigned as $\mathbf{C}$ and $\mathbf{K}$, respectively (Figure $1 \mathrm{a}-\mathrm{c}$ ). Scheme 1 shows the two pathways leading to $m / z 149$ through $\mathbf{C}$ and $\mathbf{K}$ corresponding to the McLafferty +1 rearrangement and the loss of alkoxy radical pathways, respectively. The $\mathrm{R}_{1}$ group (Scheme 1) is equal to $\mathrm{R}_{2}$ for DBP, DnOP, and DEHP; for BBP, $R_{1}$ is a benzyl group and $R_{2}$ is a butyl group.

The pathways were studied by both MSMS and theoretical calculations at a B3LYP level of theory using 6-311 G $(\mathrm{d}, \mathrm{p})$ basis sets. To determine energetically stable structures, 
(a)

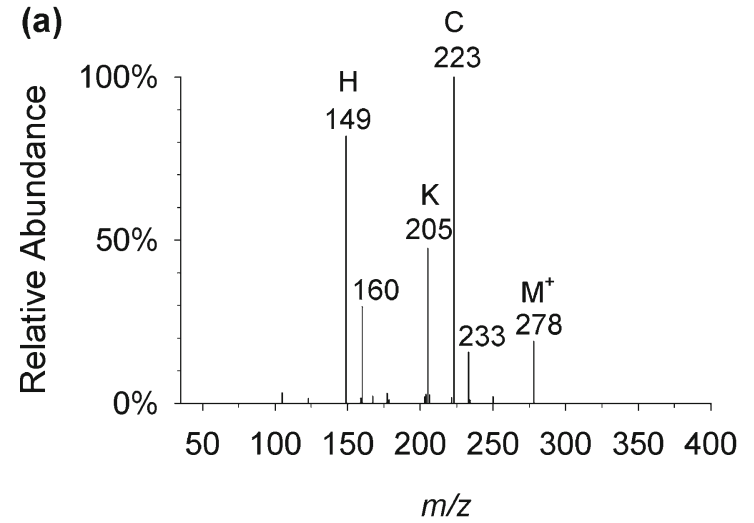

(b)

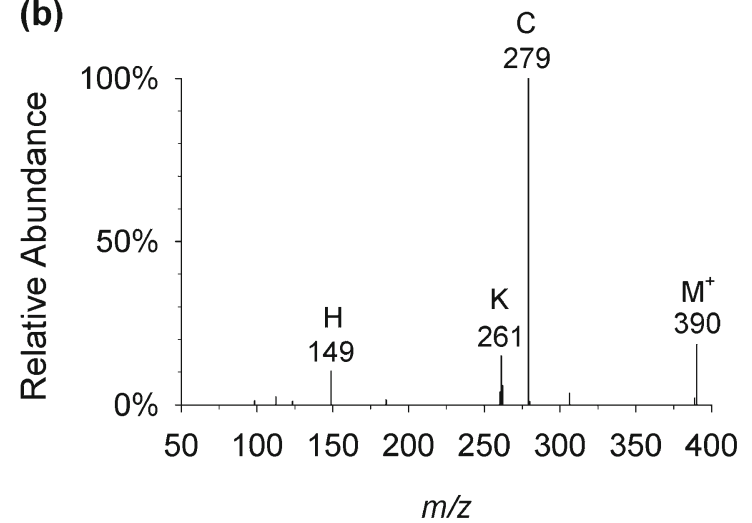

(c)

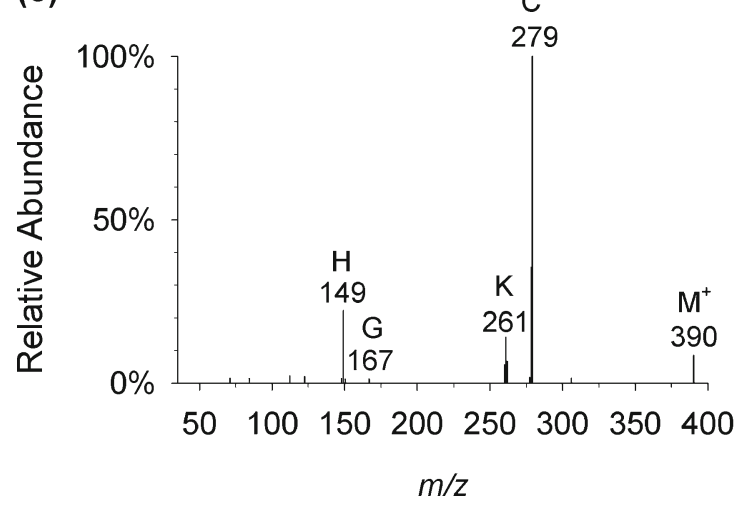

(d) $\mathrm{C}$

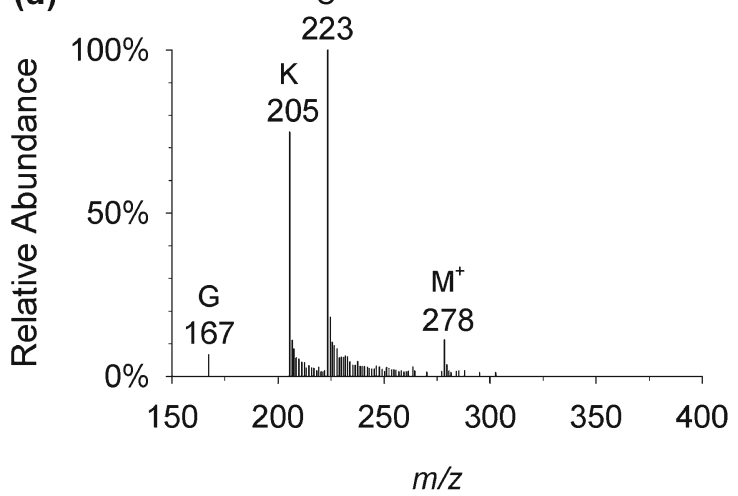

(e) $\mathrm{C}$
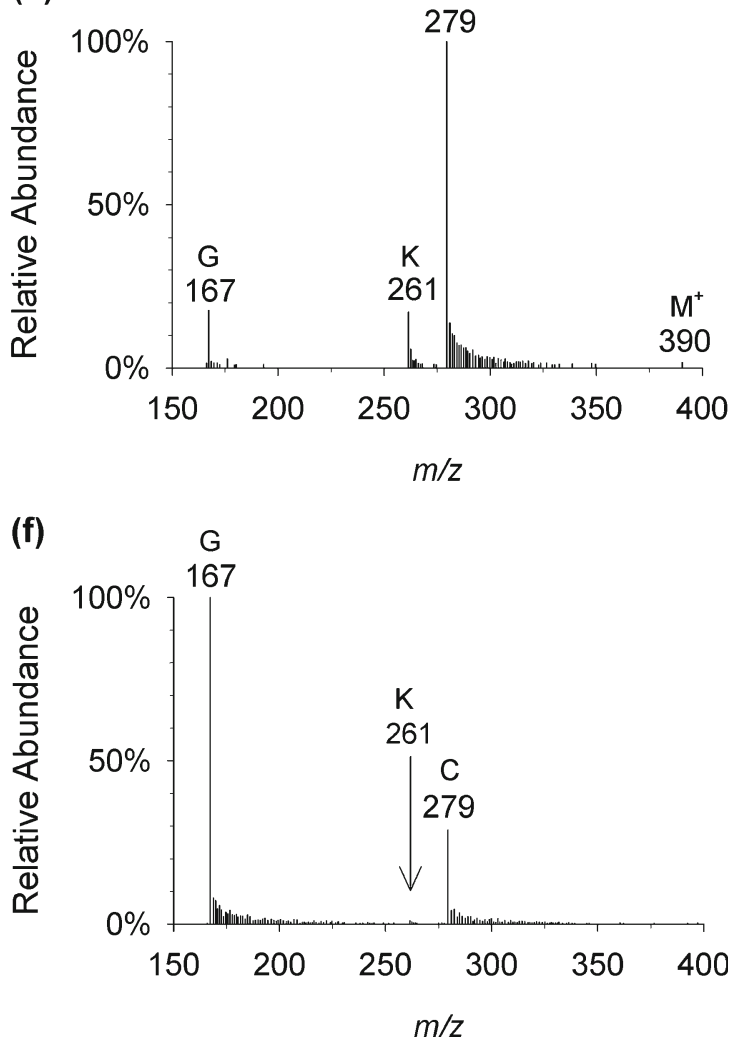

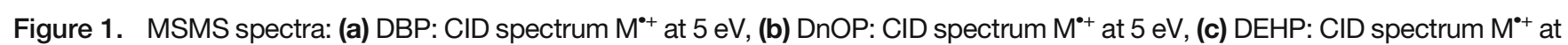
$5 \mathrm{eV}$, (d) DBP: $\mathbf{H}(\mathrm{m} / z$ 149) precursor ions spectrum at $10 \mathrm{eV}$, (e) DnOP: $\mathbf{H}(\mathrm{m} / z$ 149) precursor ions spectrum at $10 \mathrm{eV}$, and (f) DEHP: H $(\mathrm{m} / z$ 149) precursor ions spectrum at $10 \mathrm{eV}$

both cyclic and acyclic ions were considered in these calculations. Spectra were obtained either by product or precursor ions scanning. DBP, DEHP, and DnOP fragment by the two major pathways; BBP showed a characteristic fragmentation pathway. Each of these pathways deserves a closer look to both spectra and calculations that follows.

\section{McLafferty +1 Fragmentation Pathway}

Fred McLafferty described the "McLafferty+1" rearrangement as a stepwise transfer of two hydrogens from the alkoxy alkyl chain of an ester to the oxygens of the ester group (or similar functional groups) [20]. The first step is the traditional McLafferty rearrangement to give a distonic ion. The second step is the transfer of a second $\mathrm{H}$ from the alkyl group to the ester group oxygen leading to the elimination of an alkene radical from the $\mathrm{M}^{*+}$. The mechanism for the transfer of the second hydrogen has been suggested to proceed through an ion molecule complex [21-23]. It is well documented that fragmentation in the gas phase may take place through ion molecule complexes [24, 25].

\section{Transition States of the McLafferty Rearrangement}

Scheme 1 shows the McLafferty rearrangement to give the distonic ion $\mathbf{A}$; the rearrangement involves the transfer of a 


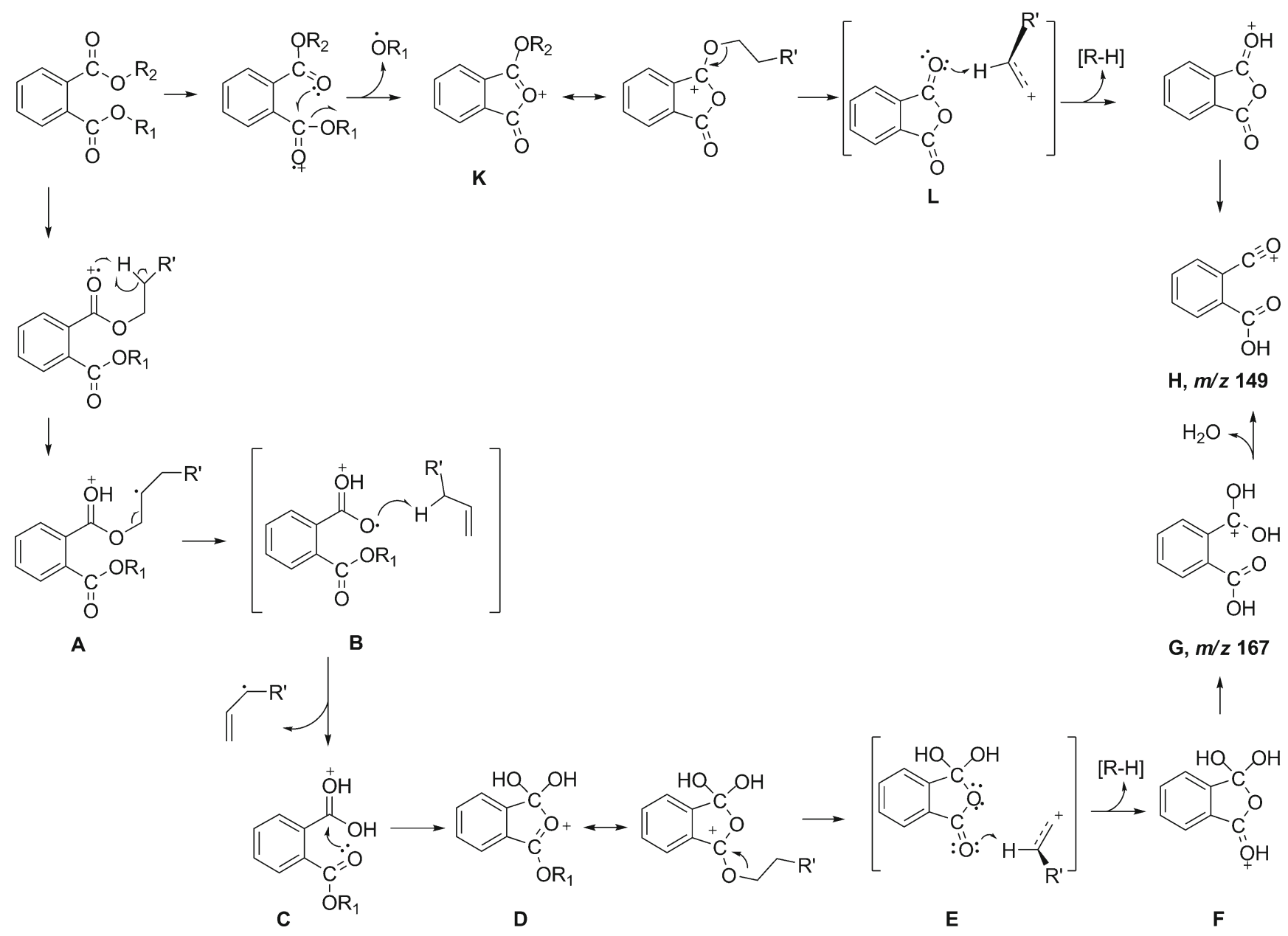

Scheme 1. Phthalate fragmentation mechanism

$\mathrm{H}$ from the $\beta$-carbon of the alkyl chain to the carbonyl oxygen. The H-rearrangement from $\mathrm{M}^{\circ+}$ proceeds via a sixmembered ring transition state. The transition state structures found by QST2 methods for DBP, DnOP, and DEHP are depicted in Figure 2. Table 1 shows the activation energy for the McLafferty rearrangement with DEHP having the smallest energy barrier of $0.4 \mathrm{kcal} / \mathrm{mol}$.

The structure of the transition state for DBP and DnOP has the migrating $\mathrm{H}$ at $1.3 \AA$ from the carbon it departs, and it is at $1.4 \AA$ from the oxygen it joins (Figure 2a, b). For DEHP, the $\mathrm{H}$ was closer to the carbon it departs at a distance of $1.2 \AA$, and it was $1.5 \AA$ from the oxygen it joins (Figure $2 \mathrm{c}$ ).

The overlap population of the transition state was determined from the density matrix as the sums of the offdiagonal elements between atoms in the Mulliken population analysis. Table 2 shows that all values of the overlap populations between the migrating $\mathrm{H}$ and the $\mathrm{C}$ it departs and $\mathrm{O}$ it joins are positive, indicating bonding characteristics between these atoms. The bonding between the migrating $\mathrm{H}$ and $\mathrm{O}$ it joins is stronger for DBP and DnOP than for DEHP; this is consistent with the bond distances shown in Figure 2. Note that the migrating $\mathrm{H}$ in the transition state maintains a stronger bond with $\mathrm{C}$ than with $\mathrm{O}$.
The NPA charge analysis in Table 2 shows less negative charge on the C of DEHP than of DBP and DnOP. This is consistent with the fact that the $\mathrm{C}$ in DEHP is a tertiary $\mathrm{C}$, and it is a secondary $\mathrm{C}$ in DBP and DnOP. Note that the decreased charge of the $\mathrm{C}$ in DEHP is not reflected on the NPA charge of the migrating $\mathrm{H}$. The NPA charge on the migrating $\mathrm{H}$ is quite similar for all transition states. The smaller negative charge on the $\mathrm{C}$ for DEHP, compared to DBP and DnOP, did not affect bonding between the migrating $\mathrm{H}$ and the $\mathrm{C}$, as could be verified by the electron density overlap.

Figure $2 \mathrm{~d}$, e, f depict the spin density surfaces (or difference between $\alpha$ and $\beta$ densities) for the transition state structures. Knowledge of spin distribution has a mechanistic importance to provide computational evidence of the intramolecular radical attack on $\mathrm{H}$ by the $\mathrm{O}$ it joins. Note that the spin density is distributed around the part of the molecule where the rearrangement is taking place. Also, Figure 2d, e, f show that the spin density is delocalized over the aromatic ring and the ester group involved in the rearrangement step. The patterns of spin density between the migrating $\mathrm{H}$ and the $\mathrm{O}$ it joins for all transition states are quite similar. For DEHP, the $\mathrm{H}$ to be transferred was $1.55 \AA$ from the $\mathrm{O}$; however, there is a significant spin density distribution 
(a)

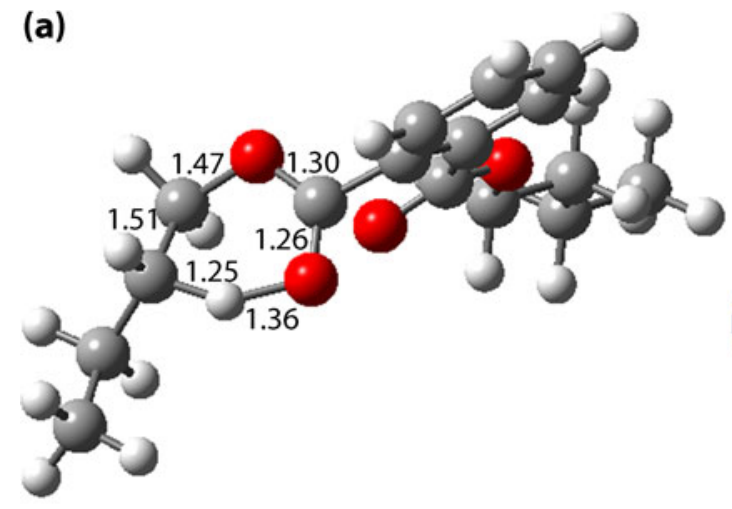

(b)

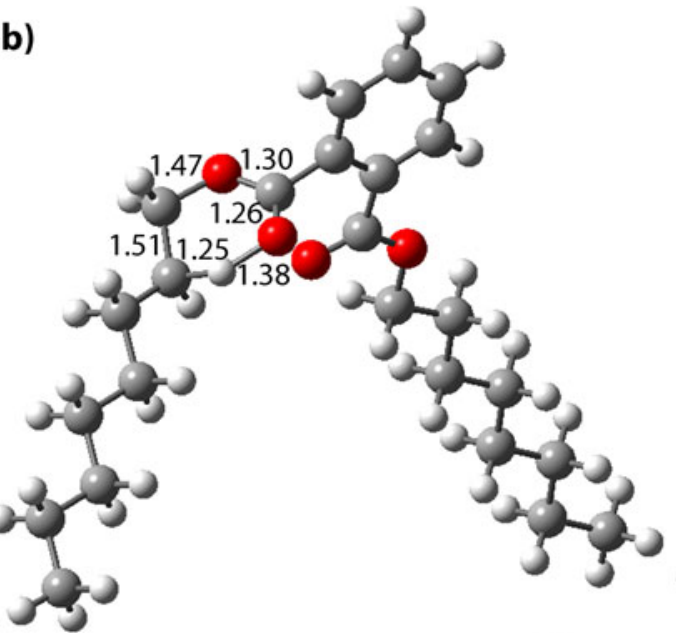

\section{(c)}

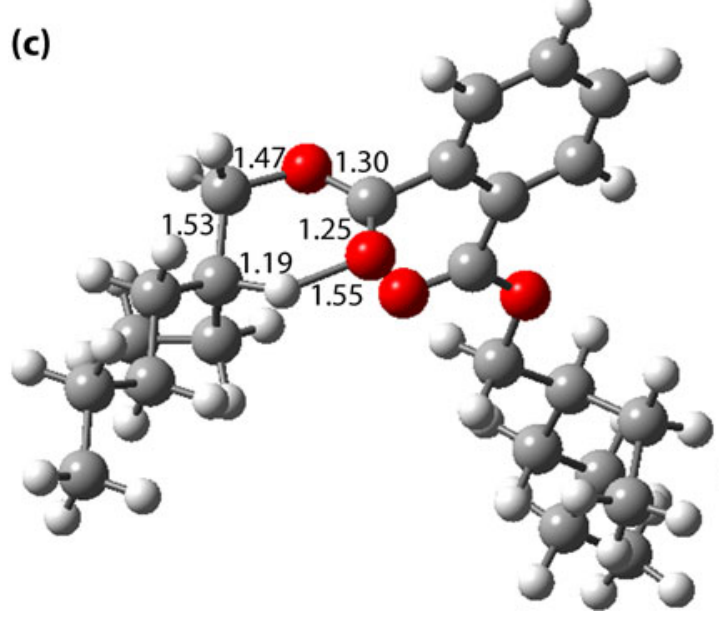

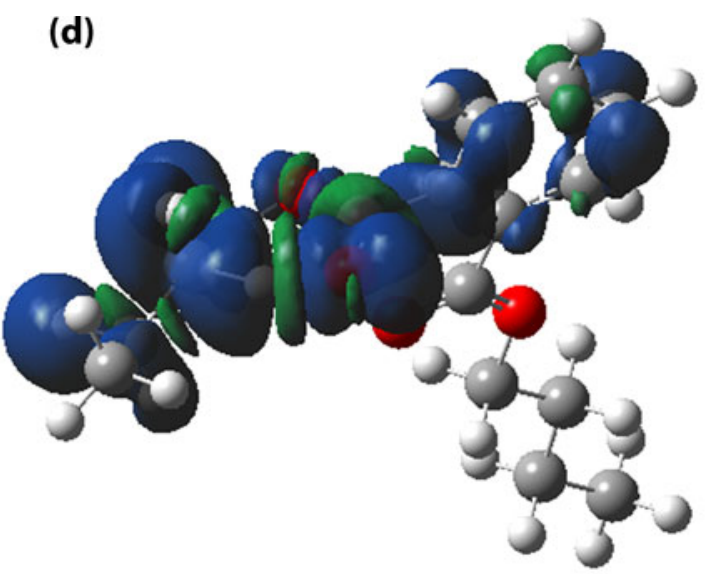

(e)

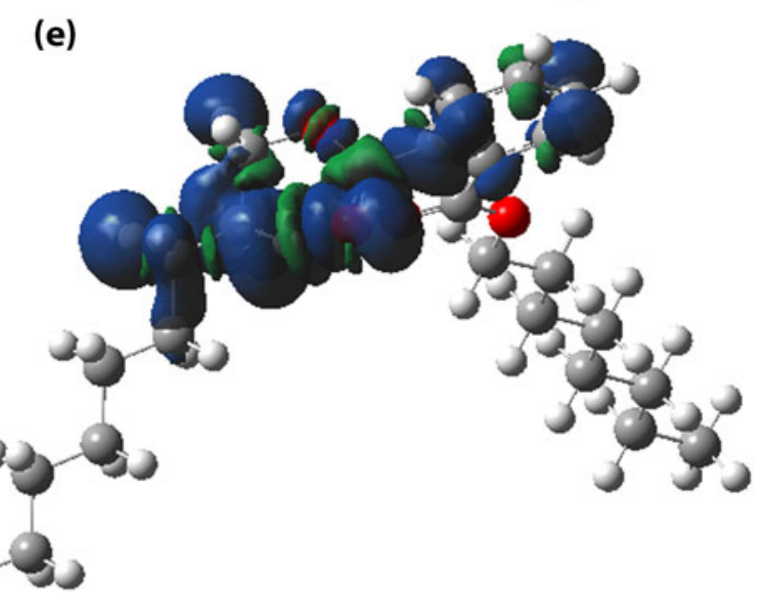

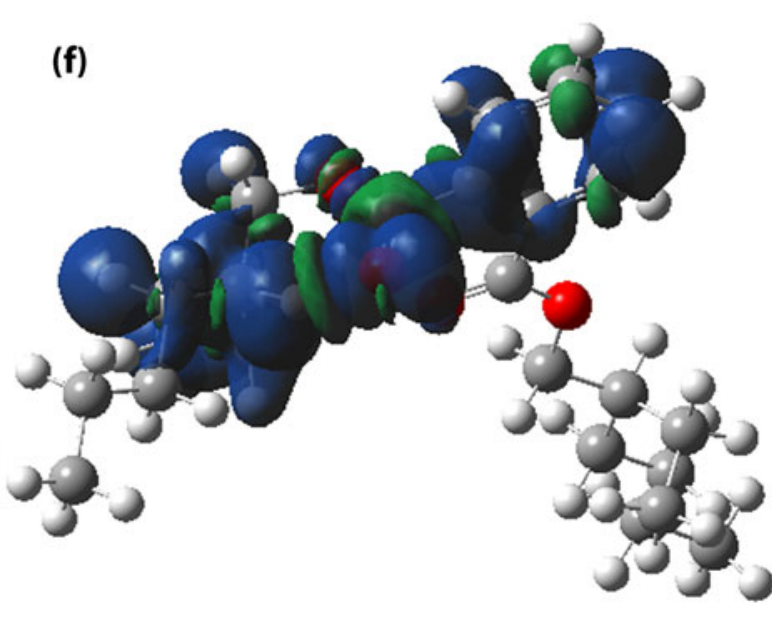

Figure 2. Optimized transition state structures: (a) DBP, (b) DnOP, and (c) DEHP. Spin density surfaces of the transition states: (d) DBP, (e) DnOP, and (f) DEHP

around the two atoms (Figure 2d) that is consistent with the mechanism in Scheme 1.

The B3LYP intrinsic reaction coordinates (IRC or the steepest descent from the transition state leading to the product in the forward direction and to the reactant in the reverse direction) was calculated for all transition state structures. The structures from IRC results led to the correct reactant/product, therefore, confirming that the transition states are those for a McLafferty reaction.

\section{Modeling Radical Cation Molecule Complex}

The transfer of the second $\mathrm{H}$ from the McLafferty product A takes place through an ion molecule complex. As the two fragments start to separate the charge is partitioned according to Stevenson's rule [26, 27]; therefore, Scheme 1 shows the positive charge to remain on the $\mathrm{O}$.

Geometry optimization of the complexes was performed without constraints. Figure 3 depicts the optimized geo- 
Table 1. Change in Free Energies and Total Entropies of the Fragmentation Pathways

\begin{tabular}{|c|c|c|c|c|}
\hline \multirow[t]{2}{*}{ Compound } & \multicolumn{3}{|c|}{$\Delta \mathrm{G}^{\mathrm{a}}$} & \multirow{2}{*}{$\frac{\Delta \mathrm{S}_{\text {total }}^{\mathrm{b}}}{6-311 \mathrm{G}(\mathrm{d}, \mathrm{p})}$} \\
\hline & $4-31 \mathrm{G}(\mathrm{d}, \mathrm{p})$ & $6-311 \mathrm{G}$ & 6-311 G(d,p) & \\
\hline \multicolumn{5}{|l|}{$\mathrm{M}^{\cdot+} \rightarrow \mathrm{TS}$} \\
\hline DBP & 5.2 & 4.9 & 5.5 & -5.4 \\
\hline DnOP & 5.9 & 6.1 & 6.2 & -6.0 \\
\hline DEHP & 0.0 & -1.3 & 0.4 & -4.8 \\
\hline \multicolumn{5}{|l|}{$\mathrm{TS} \rightarrow \mathrm{A}$} \\
\hline DBP & -23.3 & -25.2 & -23.2 & 6.0 \\
\hline DnOP & -23.2 & -25.9 & -23.3 & 5.1 \\
\hline DEHP & -25.9 & -28.9 & -26.3 & 9.6 \\
\hline \multicolumn{5}{|l|}{$\mathrm{A} \rightarrow \mathrm{B}$} \\
\hline DBP & 20.8 & 17.3 & 15.9 & 6.3 \\
\hline DnOP & 19.5 & 16.4 & 15.4 & 6.3 \\
\hline DEHP & 16.5 & 14.7 & 13.1 & 1.4 \\
\hline \multicolumn{5}{|l|}{$B \rightarrow C$} \\
\hline DBP & -29.8 & -29.0 & $-25.9(2.6)^{\mathrm{e}}$ & 28.9 \\
\hline DnOP & -28.3 & -22.0 & $-24.4(3.7)^{\mathrm{e}}$ & 32.1 \\
\hline DEHP & -16.8 & -13.4 & $-15.9(10.4)^{\mathrm{e}}$ & 31.6 \\
\hline \multicolumn{5}{|l|}{$\mathrm{C} \rightarrow \mathrm{E}$} \\
\hline DBP & 59.2 & 53.1 & 50.1 & 7.2 \\
\hline DnOP & 57.6 & 47.2 & 48.9 & 6.7 \\
\hline DEHP & 36.7 & 28.7 & 31.9 & 14.2 \\
\hline \multicolumn{5}{|l|}{$\mathrm{E} \rightarrow \mathrm{G}$} \\
\hline DBP & -23.5 & -21.2 & -24.7 & 34.5 \\
\hline DnOP & -22.0 & -19.5 & -23.6 & 35 \\
\hline DEHP & -11.1 & -6.5 & -12.6 & 29.5 \\
\hline $\mathrm{G} \rightarrow \mathrm{H}$ & 12.0 & 6.9 & 0.4 & 40.1 \\
\hline \multicolumn{5}{|l|}{$\mathrm{M}^{++} \rightarrow \mathrm{K}$} \\
\hline DBP & 11.9 & 7.6 & 10.1 & 36.9 \\
\hline $\mathrm{BBP}^{\mathrm{c}}$ & 18.2 & 13.4 & 16.0 & 39.5 \\
\hline $\mathrm{BBP}^{\mathrm{d}}$ & 17.2 & 13.4 & 14.6 & 42.2 \\
\hline DnOP & 13.1 & 9.2 & 11.3 & 37.1 \\
\hline DEHP & 8.4 & 3.8 & 6.9 & 40.9 \\
\hline \multicolumn{5}{|l|}{$\mathrm{K} \rightarrow \mathrm{L}$} \\
\hline DBP & 24.4 & 21.0 & 21.0 & 8.9 \\
\hline BBP & 24.4 & 21.0 & 21.0 & 8.9 \\
\hline DnOP & 21.9 & 18.3 & 18.6 & 10.8 \\
\hline DEHP & 6.5 & 1.0 & 3.4 & 13.0 \\
\hline \multicolumn{5}{|l|}{$\mathrm{L} \rightarrow \mathrm{H}$} \\
\hline DBP & -11.6 & -12.2 & -13.6 & 32.1 \\
\hline BBP & -11.6 & -12.2 & -13.6 & 32.1 \\
\hline DnOP & -9.3 & -9.6 & -11.2 & 32.2 \\
\hline DEHP & 2.8 & 4.9 & 0.9 & 29.9 \\
\hline $\mathrm{M}^{++} \rightarrow \mathrm{M}$ & -22.9 & -21.8 & -22.4 & -3.3 \\
\hline $\mathrm{M} \rightarrow \mathrm{N}$ & 16.7 & 16.4 & 13.7 & 38.9 \\
\hline
\end{tabular}

${ }^{\mathrm{a}}$ In units of $\mathrm{kcal} / \mathrm{mol}$ at $298 \mathrm{~K}$

${ }^{\mathrm{b}}$ In units of $\mathrm{cal} / \mathrm{mol} \mathrm{K}$ at $298 \mathrm{~K}$

${ }^{c}$ loss of butoxy radical

${ }^{d}$ loss of benzylox radical

${ }^{\mathrm{e}}$ In parenthesis corresponds to free energy for the loss of a vinyl radical

metries of the ion molecule complexes with a preferred interaction between the alkene and the charged fragment through the Cs and Hs of the alkene's double bond. The closest distance between a $\mathrm{H}$ from the alkene and the $\mathrm{O}$ radical of the second partner is in the range of $2.37-2.40 \AA$ (Figure 3); the $\mathrm{O}$ radical (Figure 3) is at a distance range of 2.25-2.28 $\AA$ from the terminal $\mathrm{C}$ of the alkene group.

Molecular orbital (MO) analysis of $\mathbf{B}$ indicates that part of the lowest occupied molecular orbital (LUMO), molecular orbital no. 76 for DBP and molecular orbital no. 108 for DnOP, has an overlap region between the two partners of $\mathbf{B}$; this suggested that the LUMO is not antibonding between the $\mathrm{O}$ and the $\mathrm{C}$ of the alkene group. Such bonding characteristic of a LUMO has been previously described [28]. In the case DEHP, the overlap of the LUMO was not observed because of the relative orientation of the two partners of the complex.

The formation of the DBP and DnOP complexes required energy of about $16 \mathrm{kcal} / \mathrm{mol}$ (Table 1). The excess energy of the complex relative to the distonic ion $\mathbf{A}$ has been previously suggested to be sufficient to allow the reorientation of the two partners that make up the complex [25, 29]. The formation of Complex $\mathbf{B}$ from the distonic ion of DEHP was exceptionally exergonic (Table 1). As expected, the formation of all complexes was entropically favored (by $6 \mathrm{cal} / \mathrm{mol} \mathrm{K}$ ). The increase of the entropy was contributed mainly by an increase in the vibrational entropy contribution of the complex.

\section{Transfer of Hydrogen Through Radical Cation Molecule Complex}

For the McLafferty +1 rearrangement, the transfer of the second $\mathrm{H}$ has been proposed to give an allylic radical [22, 30] or a vinyl radical [31]; an allylic or a vinyl radical elimination is possible because the two fragments within the complex are allowed to rotate [26]. The cation molecule complexes (B) show that the vinylic $\mathrm{Hs}$ are closer to $\mathrm{C}-\mathrm{O} \bullet$ at a distance range of $2.37-2.40 \AA$ (Figure 3). The distance between the $\mathrm{CO} \cdot$ and the allylic $\mathrm{H}$ is longer than the vinylic $\mathrm{H}$ (Figure 3). All B complexes show a distance of $2.3 \AA$ between $\mathrm{CO} \cdot$ and the terminal $\mathrm{C}$. Energetically, the allylic radical is far more stable than the vinylic radical; therefore, the mechanism in Scheme 1 shows the allylic isomer. This assumption is valid because, as stated earlier, the two partners within the complex are allowed to rotate. Also, Table 1 shows that the loss of either an allylic or a vinylic $\mathrm{H}$ is energetically feasible under the MS conditions. Loss of an

Table 2. Natural Population Analysis of the Migrating H and the Bonds Around It

\begin{tabular}{|c|c|c|c|}
\hline Description & DBP & DnOP & DEHP \\
\hline Overlap population between migrating $\mathrm{H}$ and $\mathrm{C}$ it departs & 0.269 & 0.268 & 0.308 \\
\hline Overlap population between migrating $\mathrm{H}$ and $\mathrm{O}$ it joins & 0.115 & 0.115 & 0.075 \\
\hline Bond order between migrating $\mathrm{H}$ and $\mathrm{C}$ it departs & 0.573 & 0.577 & 0.670 \\
\hline Bond order between migrating $\mathrm{H}$ and $\mathrm{O}$ it joins & 0.371 & 0.360 & 0.243 \\
\hline NPA charge of the migrating $\mathrm{H}$ in the TS & 0.339 & 0.340 & 0.331 \\
\hline NPA charge of $\mathrm{C}$ in the TS as $\mathrm{H}$ migrates & -0.269 & -0.271 & -0.148 \\
\hline NPA charge of $\mathrm{O}$ in the TS as $\mathrm{H}$ joins it & -0.442 & -0.444 & -0.414 \\
\hline
\end{tabular}


(a)

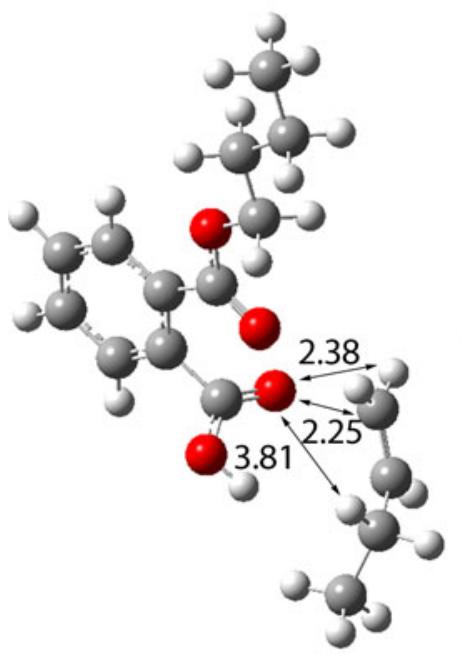

(b)

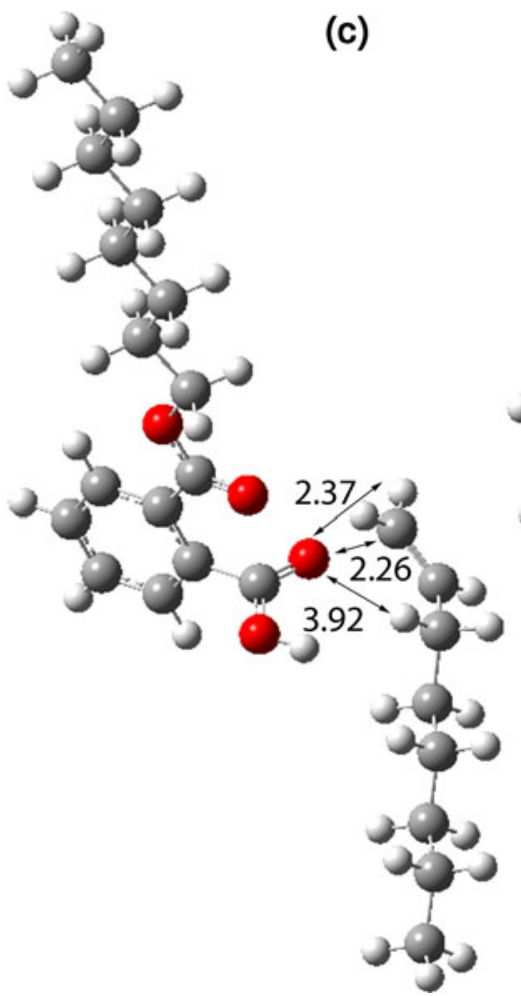

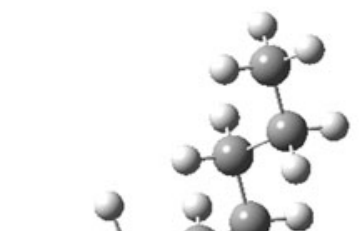
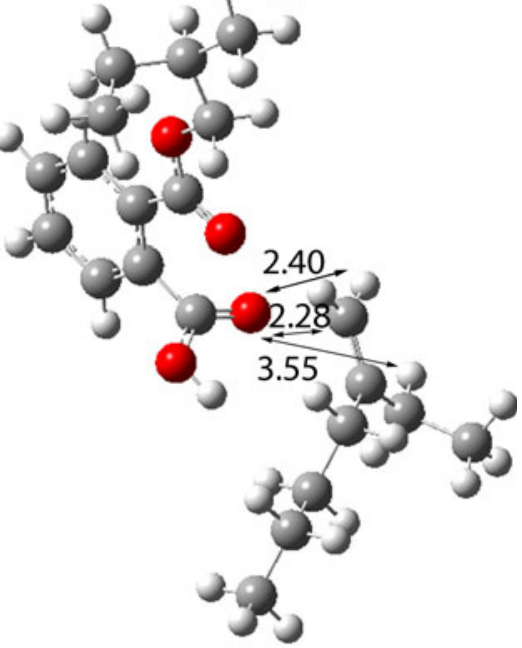

Figure 3. Optimized structures of radical cation molecule Complex B for: (a) DBP, (b) DnOP, and (c) DEHP

allylic $\mathrm{H}$ is highly exergonic and loss of a vinylic $\mathrm{H}$ is slightly endergonic (Table 1).

\section{Structure of McLafferty +1 Product Ion}

The product of the McLafferty +1 rearrangement, $\mathbf{C}$, is a closed shell ion that has two resonance structures involving the protonated carboxylic acid group. McLafferty and Tureček described such resonance stabilization as an added driving force for the process [20]. Two structures of $\mathbf{C}$ were optimized: (a) type 1: with hydroxyl group H-bonded to the ortho-carbonyl oxygen, and (b) type 2: with the plane of the $\mathrm{HOCOH}$ group almost perpendicular to the plane of the ester group. Figure 4 depicts the structures of the two types of $\mathbf{C}$ for DBP. Table 3 shows that the type 1 structure of $\mathbf{C}$ with H-bond is energetically favored; therefore, it was used in the free energy calculations. The formation of the McLafferty rearrangement product $(\mathbf{C})$ is exergonical and entropically favored.

\section{Cleavage of an Alkyl Group from McLafferty Product Ion}

In this step, $\mathrm{R} 1$ in $\mathbf{C}$ is lost with a net transfer of one $\mathrm{H}$ from $\mathrm{R} 1$ to an $\mathrm{O}$ (Scheme 1). The $\mathrm{H}$ transfer has been previously reported for closed shell cations; however, the mode of transfer has not been addressed adequately [32, 33]. There are few reports that suggested a McLafferty type rearrange- ment of closed shell cations [32]. Also, there is ample evidence for the possibility of $\mathrm{H}$ transfer through ion molecule complexes [33]. Therefore, both types of $\mathrm{H}$

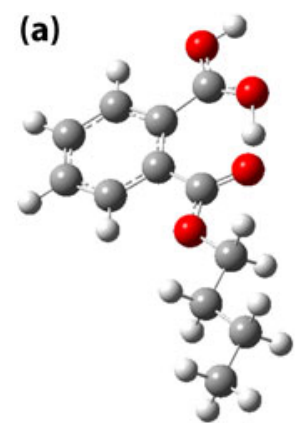

(c)

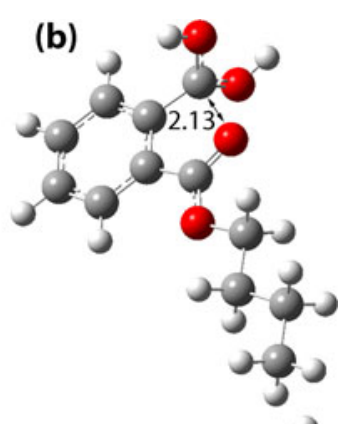

(d)

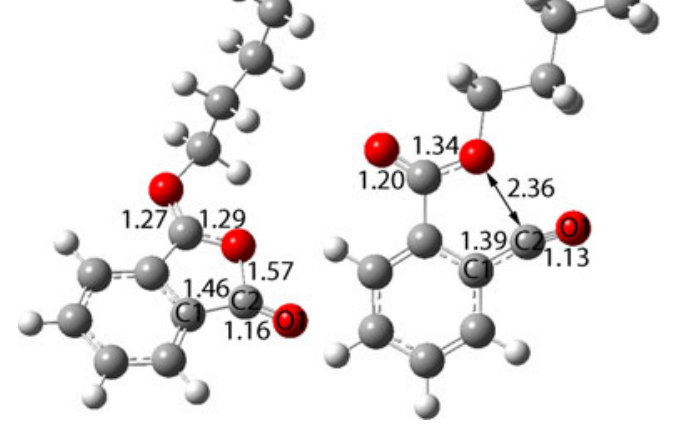

Figure 4. Optimized structures: (a) Type-1 McLafferty Product of DBP, (b) Type-2 McLafferty Product of DBP, (c) Cyclic K of $\mathrm{DBP}$, and (d) Acyclic K of DBP 
Table 3. Difference in Free Energies $(\mathrm{kcal} / \mathrm{mol})$ at B3LYP Level of Theory Between Type 1 and Type 2 Structure of Ion $\mathbf{C}$

\begin{tabular}{lccc}
\hline Ion C & $4-31 \mathrm{G}(\mathrm{d}, \mathrm{p})$ & $6-311 \mathrm{G}$ & $6-311 \mathrm{G}(\mathrm{d}, \mathrm{p})$ \\
\hline DBP & -22.9 & -22.6 & -17.5 \\
BBP & -29.8 & -29.9 & -24.8 \\
DEHP & -16.5 & -16.3 & -13.2 \\
DnOP & -22.9 & -18.6 & -19.4 \\
\hline
\end{tabular}

transfers, the McLafferty rearrangement and the cation molecule complexes, were considered: (a) transfer of the $\mathrm{H}$ from a $\beta$ position of the alkyl chain through a cyclic transition state, and (b) modeling cation molecule complexes that project the two partners of the complex to a $\mathrm{H}$ transfer process. Attempts to locate the transition states with QST2 and QST3 options in the Gaussian software did not lead to transition states. On the other hand, stable cation molecule complexes were modeled to account for the $\mathrm{H}$ transfer. Therefore, Scheme 1 shows the steps leading to the formation of complex $\mathbf{E}$ from $\mathbf{C}$.

An initial intramolecular carbonyl-O attack at the protonated carbonyl-C of $\mathbf{C}$ leads to D (Scheme 1). Intuition suggests that the intramolecular attack proceeds through the carbonyl-O attack instead of the alkoxy-O. Such carbonyl O intramolecular cyclization was recently proposed in the fragmentation of metastable DMP molecular ions [34] and positive chemical ionization fragmentation of phthalates [6]. In an earlier study, the EI cyclization mechanism was reported through the alkoxy-O attack [2]. The intermediate D can undergo a bond-cleavage leading to Complex (E) as shown in Scheme 1.

\section{Modeling Hyperconjugated Cation Molecule Complex E}

Cleavage of R1 from $\mathbf{D}$ leads to the formation of Complex $\mathbf{E}$ that involves a primary carbocation together with a gem-diol analog of phthalic anhydride. Initial attempts to optimize models of ion molecule complexes of DBP led the two partners of the complex to merge and go back to the reactant instead of the formation of a complex. During these attempts, the modeled-complexes involved ad hoc structures without a detailed study of a wide potential energy surface because such a study required extensive computational time. It appears that the carbocation of R1 cannot be treated as a traditional gas phase carbocation because there is the influence of the second partner in the complex; note that a free gas phase carbocation $\mathrm{R}^{+}$can be optimized. It appears that the interaction between a classical primary carbocation with the neutral partner in the complex cannot be ignored. During the optimization at B3LYP/6-311 g(d,p) level, an ion molecule complex of DEHP converged to a more stable complex involving a non-classical hyperconjugated carbocation. It turns out that the carbocation of DEHP has to undergo a rearrangement from primary to secondary carbocation that facilitates the formation of the hyperconjugated cation (vide infra); this rearrangement is similar to 1,2hydride shifts in carbocations that are quite common [35]. Therefore new complexes of $\mathbf{E}$ involving hyperconjugated carbocations were modeled that led to stable ion molecule structures. Hyperconjugation has been reported to contribute to the stability of carbenium ions $\left(\mathrm{R}_{3} \mathrm{C}^{+}\right)$[36]. In our case, hyperconjugative stability is attributed to the overall stability of the gas-phase carbocation molecule complex.

Figure 5 shows the most important bond lengths of the hyperconjugated carbocation molecule complexes with a carbenium ion center at $\mathrm{C} 3$. The $\mathrm{C} 1-\mathrm{C} 2$ bond is significantly elongated (Figure 5) relative to a typical $\mathrm{C}-\mathrm{C}$ bond of $1.53 \AA$ that was calculated at the same level of theory for ethane; such elongation of a $\beta \mathrm{C}-\mathrm{C}$ (relative to the carbenium ion center) has been previously reported [36]. Also, the calculated $\mathrm{C} 2-\mathrm{C} 3$ bond lengths are significantly shorter than a normal $\mathrm{C}-\mathrm{C}$ single bond length (Figure 5). The $\mathrm{C} 2-\mathrm{C} 3$ bond length of $1.39 \AA$ was slightly longer than a typical $\mathrm{C}=$ $\mathrm{C}$ bond length of $1.36 \AA$ in ethene that was calculated at the same level of theory.

The $\mathrm{C} 1 \mathrm{C} 2 \mathrm{C} 3$ bond angles were 73,73 , and $88^{\circ}$ for DBP, DnOP, and DEHP, respectively. The $\beta \mathrm{C}-\mathrm{C}$ in $\mathbf{L}$ is shown in Figure 5 to be perpendicular to the plane of the carbenium ion center because the $\mathrm{C} 1 \mathrm{C} 2 \mathrm{C} 3 \mathrm{H} 1$ dihedral angles were 91 , 91 , and $81^{\circ}$ for DBP, DnOP, and DEHP, respectively. The structure of $\mathbf{L}$ for DEHP was quite different from DBP and DnOP because $\mathrm{C} 1$ of DEHP, as shown in Figure $5 \mathrm{c}$, is normally attached to $\mathrm{C} 3$; however, optimization led to a stable structure with $\mathrm{C} 1$ migration to $\mathrm{C} 2$. This observation shows substituent effects on the hyperconjugated carbocation that leads to a group migration to give a more stable carbocation; group migration in DEHP leads to a secondary carbocation while such migration in DBP and DnOP does not enhance the stability of the carbocation.

Formation of $\mathbf{E}$ required 50,49 , and $32 \mathrm{kcal} / \mathrm{mol}$ for DBP, DnOP, and DEHP, respectively (Table 1). The excess energy allows reorientation of the two partners within the complex as previously described $[25,29]$. On the other hand, formation of $\mathbf{G}$ is an exergonic process and entropically favored (Table 1).

\section{Structure of $\mathrm{m} / \mathrm{z} 167$}

Optimization of the cyclic structure $\mathbf{F}$ led to opening of the five-membered ring. Figure $6 \mathrm{a}$ shows $\mathbf{G}$, an open structure of $\mathbf{F}$, with an NBO charge of +0.933 for the carbocation center. The plane of the trigonal planar carbocation is almost perpendicular to the ortho-carbonyl-O. The distance between the carbonyl-O and the carbocation center was $2.16 \AA$. On the basis of calculated bond distances, the closed structure of $\mathbf{F}$ is proposed to open up to give $\mathbf{G}$ (Scheme 1). 
(a)

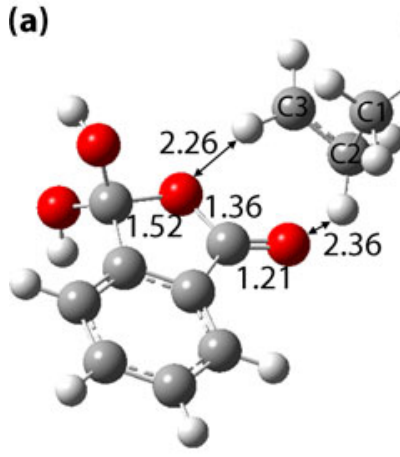

(b)

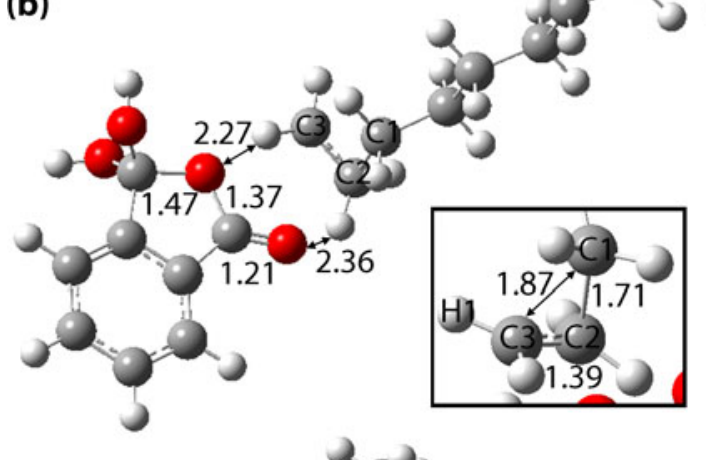

(c)
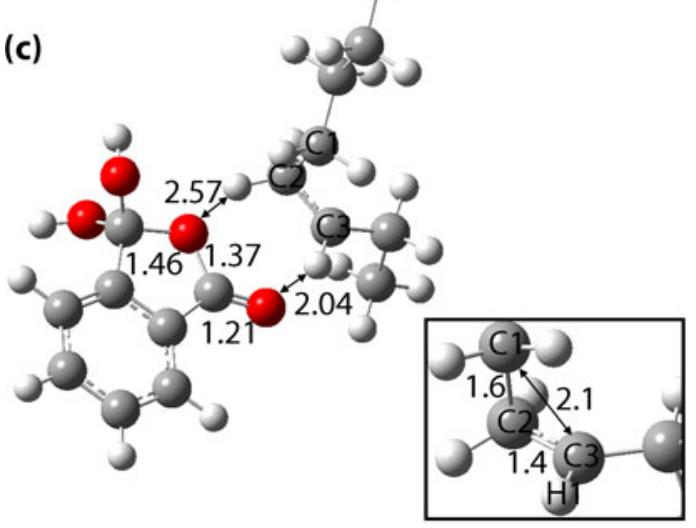

(d)
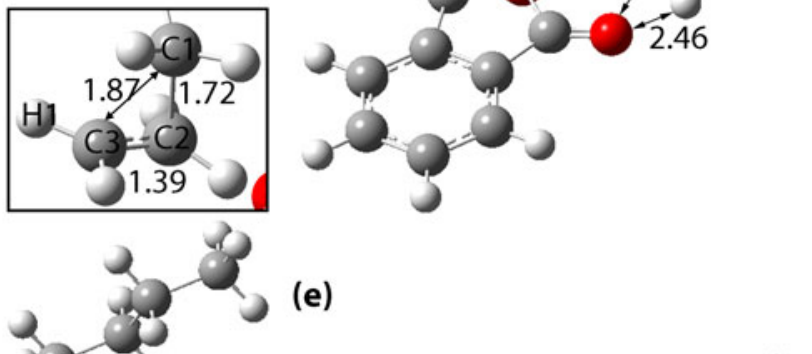
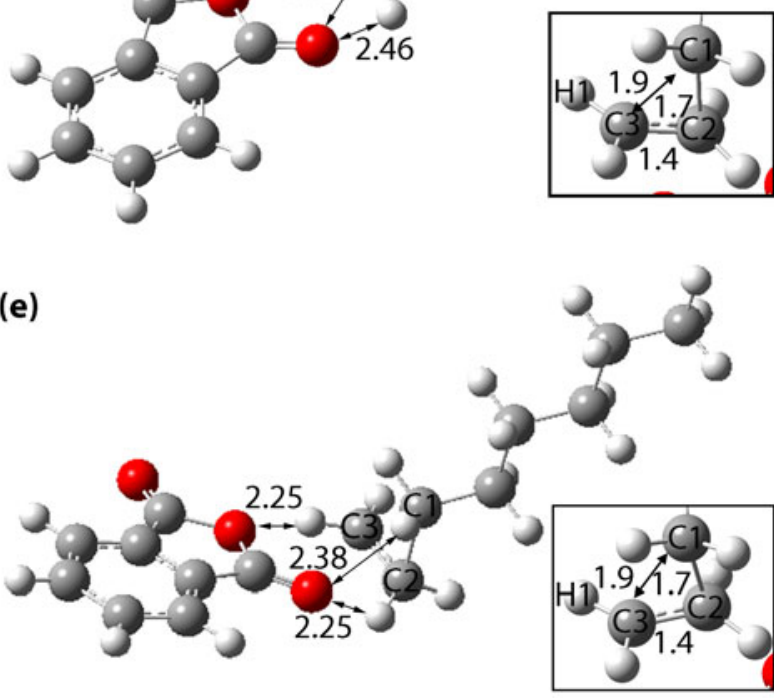

(f)

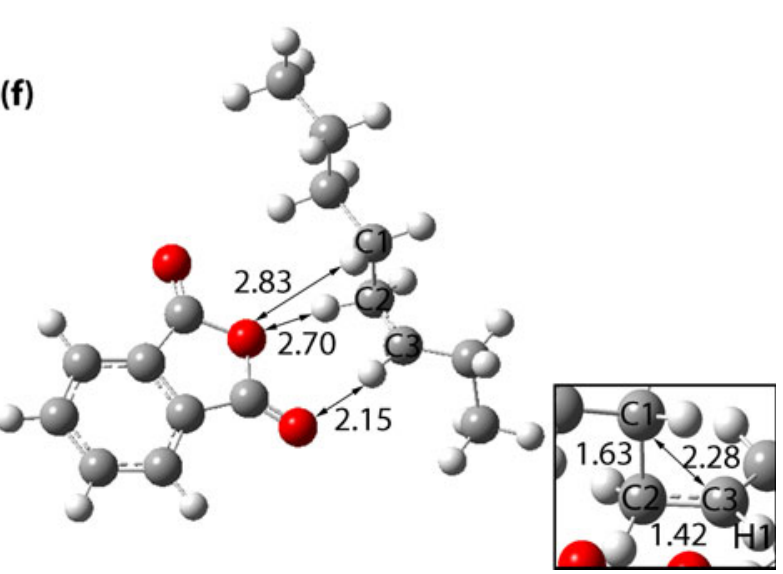

Figure 5. Optimized structure of hyperconjugated cation molecule complexes: (a) E of DBP, (b) E of DnOP, (c) E of DEHP, (d) $\mathbf{L}$ of DBP, (e) $\mathbf{L}$ of DnOP, and (f) $\mathbf{L}$ of DEHP

\section{Structure of $m / z 149$}

Table 1 shows a small free energy change $(\Delta \mathrm{G})$ of $0.4 \mathrm{kcal} / \mathrm{mol}$ associated with loss of water from $\mathbf{G}$ to give the protonated phthalic anhydride at $m / z 149(\mathbf{H})$. The anhydride is an important ion used for the identification of phthalates; and the protonation site of $\mathbf{H}$ was reported either at the middle-O [2] or at the carbonyl-O [37]. Also, the structure of $\mathbf{H}$ has been frequently reported with a closed anhydride ring $[2,37]$.

Structures of $\mathbf{H}$ with protonation at the carbonyl-O (H1) and the middle-O (H2) were studied by DFT methods. Figure $6 \mathrm{~b}$ and $\mathrm{c}$ shows the optimized structures of $\mathbf{H 1}$ and H2. The bond length between $\mathrm{C} 2-\mathrm{O} 2$ (Figure 6) was 1.72 and $2.44 \AA$ for $\mathbf{H 1}$ and $\mathbf{H 2}$, respectively; these distances suggested an open anhydride ring for both $\mathbf{H 1}$ and $\mathbf{H 2}$. For comparisons, Figure $6 \mathrm{~d}$ shows the optimized closed structure of phthalic anhydride with a $\mathrm{C} 2-\mathrm{O} 2$ bond length of $1.40 \AA$; thus, the $\mathrm{C} 2-\mathrm{O} 2$ bond length is significantly shorter than that observed in the carbonyl protonated H1. The H1 with a protonation at the carbonyl-O was found to be energetically favored by $6.5 \mathrm{kcal} / \mathrm{mol}$ over $\mathbf{H} 2$. Note that the difference between $\mathbf{H 1}$ and $\mathbf{H 2}$ is the orientation of $\mathrm{COOH}$ group (Figure 6); and rotation around a single bond (C3-C4) is allowed (Figure 6). Therefore the low energy structure H1 was used in the free energy calculation. 


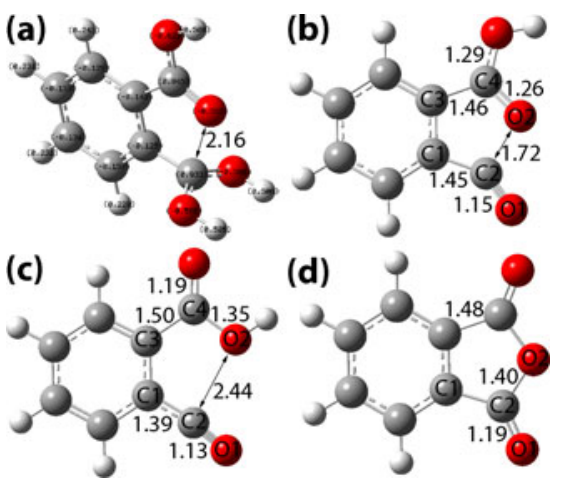

Figure 6. Optimized ion structures: (a) lon G, $m / z$ 167, (b) phthalic anhydride protonated at carbonyl oxygen (H1), $\mathrm{m} / \mathrm{z}$ 149 , (c) phthalic anhydride protonated at middle oxygen (H2), and (d) phthalic anhydride

Inspection of the highest occupied molecular orbitals (HOMOs) of $\mathbf{H}$ showed significant orbital overlap between the carbonyl-O of $\mathrm{COOH}$ group with the $\mathrm{C}$ of the ortho-CO group. The coefficients of the HOMO-2 showed that the overlap is contributed predominantly by the p-orbital of the $\mathrm{O}$. These orbital interactions are manifested in the bond angles. The $\mathrm{C} 1 \mathrm{C} 2 \mathrm{O} 1$ (Figure 6 ) bond angle was $145^{\circ}$, that is neither linear $\left(180^{\circ}\right)$ nor perfectly trigonal planar $\left(120^{\circ}\right)$; the $\mathrm{C} 1 \mathrm{C} 2 \mathrm{O} 1$ bond angle for phthalic anhydride was $131^{\circ}$. Therefore, an open structure of the protonated phthalic anhydride was proposed as shown in Scheme 1.

$\mathbf{H}$ was further studied by MSMS. At low collision energies (from 5 to $20 \mathrm{eV}$ ), CID spectra of $\mathbf{H}$ from DnOP did not show significant fragmentation. At higher collision energies (from 30 to $50 \mathrm{eV}$ ), the CID spectra showed peaks at $m / z 121,93$, and 65 . The first two peaks correspond to the loss of $\mathrm{CO}$ and $2 \mathrm{CO}$, respectively. These speaks were shifted by four mass units when deuterated-DnOP was used with all four aromatic hydrogens replaced with deuterium.

\section{Loss of Alkoxy Pathway}

Scheme 1 shows that loss of an alkoxy radical from $\mathrm{M}^{++}$ proceeds via a carbonyl-O attack on the ortho-carbonyl-C followed by loss of a neutral alkoxy radical. In an earlier study, loss of an alkoxy radical was proposed as the first step, followed by an attack by the ortho-alkoxy-O on the carbonyl-C [2]. However in that study computational evidence was not reported. Intuition suggests that the carbonyl-O ought to be more nucleophilic than the alkoxy-O of an ester group. NBO charge analysis of $\mathrm{M}^{\cdot+}$ shows more negative charge on the carbonyl-O than the corresponding alkoxy-O (Table 4). Also, the $\mathrm{M}^{\circ+}$ shows two COO groups that lie on two perpendicular planes. One of the -OCO is in a trigonal plane that is perpendicular to the ortho-carbonyl-O with a dihedral angle of about $100^{\circ}$ (Table 4). Such geometry further supports the carbonyl-O attack mechanism as shown in Scheme 1. Loss of $\bullet$ OR from $\mathrm{M}^{\bullet+}$ leads to $\mathbf{K}$.

All CID spectra show K (Figure 1a-c). All precursor ion scanning spectra (Figure 1d, e) show a peak of $\mathbf{K}$ as a precursor of $\mathbf{H}(\mathrm{m} / \mathrm{z}$ 149); however, the $\mathbf{K}$ peak for DEHP in the spectrum (Figure 1e) was significantly smaller than that observed in DBP and DnOP spectra.

Two structure of $\mathbf{K}$ were considered: cyclic and acyclic structures. Figure 4c, d show the structures of $\mathbf{K}$ for DBP. The $\mathrm{C} 1 \mathrm{C} 2 \mathrm{O} 1$ bond angle (Figure 4c, d) was 139 and $168^{\circ}$ for the cyclic and acyclic $\mathbf{K}$, respectively. The cyclic structure of $\mathbf{K}$ was energetically favored (Table 5); therefore, it was used for free energy calculations. Table 1 show that the formation of $\mathbf{K}$ is a low energy path.

Heterolytic cleavage of $\mathrm{R}$ group from the closed shell $\mathbf{K}$ leads to the formation of the ion molecule Complex $\mathbf{L}$; the

Table 4. Dihedral Angles, NBO, and Mulliken Charges of Oxygen Atoms of $\mathrm{M}^{\cdot+}$<smiles>[R]OC(=O)c1ccccc1C(=O)O[R20]</smiles>

\begin{tabular}{|c|c|c|c|c|c|c|c|c|c|}
\hline \multirow{2}{*}{ Name } & \multirow{2}{*}{$\begin{array}{c}\text { Dihedral } \\
\text { Angle }\left({ }^{\circ}\right) \\
\text { O1-O3-C1-O4 }\end{array}$} & \multicolumn{5}{|c|}{ Natural Atomic Orbital } & \multicolumn{3}{|c|}{ Mulliken } \\
\hline & & $\mathbf{0 1}$ & $\mathbf{O 2}$ & $\mathbf{O 3}$ & $\mathbf{O 4}$ & $\mathbf{0 1}$ & $\mathbf{O 2}$ & $\mathbf{O 3}$ & $\mathbf{O 4}$ \\
\hline DBP & 100 & -0.585 & -0.530 & -0.341 & -0.471 & -0.349 & -0.336 & -0.178 & -0.259 \\
\hline $\mathrm{BBP} *$ & 93 & -0.610 & -0.538 & -0.477 & -0.520 & -0.370 & -0.339 & -0.257 & -0.296 \\
\hline DEHP & 100 & -0.587 & -0.529 & -0.340 & -0.473 & -0.353 & -0.337 & -0.178 & -0.261 \\
\hline $\mathrm{DnOP}$ & 100 & -0.587 & -0.530 & -0.342 & -0.472 & -0.351 & -0.337 & -0.179 & -0.261 \\
\hline
\end{tabular}

${ }^{a} \mathrm{R} 1$ and $\mathrm{R} 2$ for BBP corresponded to the butyl and benzyl groups, respectively 
Table 5. Energy Difference Between Cyclic Ion $\mathbf{K}$ and Acyclic Ion $\mathbf{K}$

\begin{tabular}{lccc}
\hline Ion K & \multicolumn{3}{c}{ Difference in B3LYP energy $^{\mathrm{a}}$} \\
\cline { 2 - 4 } & $4-31 \mathrm{G}(\mathrm{d}, \mathrm{p})$ & $6-311 \mathrm{G}$ & $6-311 \mathrm{G}(\mathrm{d}, \mathrm{p})$ \\
\hline DBPH-ROH & -12.3 & -5.6 & -10.0 \\
BBPH(butanol) & -11.9 & -4.3 & -9.7 \\
BBPH(benzyl al) & -12.3 & -5.6 & -10.0 \\
DEHPH-ROH & -13.4 & -7.4 & -10.8 \\
DnOPH-ROH & -11.9 & -5.2 & -9.5 \\
\hline
\end{tabular}

${ }^{\text {a }}$ The energy difference=energy of cyclic $\mathbf{K}-$ energy of acyclic $\mathbf{K}$

loss of $\mathrm{R}$ from $\mathbf{K}$ is associated with the transfer of a $\mathrm{H}$ from the R group to one of the Os (Scheme 1). Similar to E, the carbocation in the optimized $\mathbf{L}$ was hyperconjugated; as expected, the phthalic anhydride partner in $\mathbf{L}$ (Figure $5 \mathrm{~d}, \mathrm{e}, \mathrm{f}$ ) has a closed five-membered ring structure. Similar to E, complex $\mathbf{L}$ of DEHP showed an alkyl group that migrates to the adjacent carbocation center (at a primary C); this rearrangement produces a secondary carbocation that is more stable than the initial primary carbocation. The bond lengths of the hyperconjugated carbocation center $(\mathrm{C} 1 \mathrm{C} 2 \mathrm{C} 3) \mathrm{DBP}, \mathrm{DnOP}$, and DEHP (Figure 5d, e, f) have similar patterns. The $\mathrm{C} 2-\mathrm{C} 3$ bond length range of 1.39-1.42 $\AA$ (Figure $5 \mathrm{~d}, \mathrm{e}, \mathrm{f}$ ) is slightly longer than a typical double bond length of $1.36 \AA$ and shorter than a single bond of $1.53 \AA$ that were calculated for ethene and ethane, respectively, at the same level of theory. The $\mathrm{C} 1 \mathrm{C} 2 \mathrm{C} 3$ bond angle was 73,74 , and $95^{\circ}$ for DBP, DnOP, and DEHP, respectively. The $\mathrm{C} 1 \mathrm{C} 2 \mathrm{C} 3 \mathrm{H} 1$ dihedral angle was 91,91 , and $85^{\circ}$ for DBP, DnOP, and DEHP, respectively; therefore, the R' bond is shown perpendicular to the plane of the carbocation center (Scheme 1). Loss of an alkene from $\mathbf{L}$ leads to the formation of $\mathbf{H}$. This loss is energetically and entropically favored.

\section{Spectra of Deuterium Labeled Phthalates}

Important peaks along the pathways were further confirmed with deuterium labeled phthalates. Fragmentation of deuterated DBP and DnOP with all four aromatic Hs replaced with deuterium were studied by MSMS (spectra in Supplemental Information). As expected, the peaks were shifted by four mass units (Supplemental Information).

\section{Mechanism for the Formation of $\mathrm{m} / \mathrm{z} 206$}

The CID spectrum of $\mathrm{M}^{\cdot+}$ from BBP showed a peak at $m / z$ 206. This peak is characteristic for BBP and was observed in its full scan spectrum [38]. The proposed mechanism leading to the formation of $\mathrm{m} / \mathrm{z} 206$ involves a $\mathrm{H}$ rearrangement to give a distonic ion followed by a neutral elimination of benzaldehyde from distonic $\mathrm{M}^{\cdot+}$ (Scheme 2). The resulting $\mathrm{m} / \mathrm{z} 206$ is stabilized by resonance. Similar mechanism for the initial $\mathrm{H}$ rearrangement was previously reported for the elimination of $\mathrm{CO}_{2}$ from methyl benzoate [39]. Table 1 shows the proposed mechanism in Scheme 2 is energetically feasible.

\section{Conclusions}

The computational study reported above provides a reasonable picture of the fragmentation pathways, including energetics and ion structures. The McLafferty rearrangement was characterized by a six-membered transition state with a low energy barrier (between 0.4 and $6.2 \mathrm{kcal} / \mathrm{mol}$ ). Bond length and bond angle calculations demonstrated that protonated phthalic anhydride does not have a closed anhydride ring. All reactions leading to the formation of ion molecule complexes (B, E, and $\mathbf{L}$ ) were endergonic; this energy requirement is suggested to allow the two partners of the complex to rotate. Such rotation can facilitate the elimination of either vinylic or allylic species. On the other hand, all dissociations involving ion molecule complexes $(\mathbf{B} \rightarrow \mathbf{C}, \mathbf{E} \rightarrow \mathbf{F}, \mathbf{L} \rightarrow \mathbf{H})$ were shown to be exergonic.

The results show that there are two types of cation molecule complexes; $\mathbf{B}, \mathbf{L}$, and $\mathbf{K}$ complexes can be conveniently distinguished as radical cation molecule complex (B) and hyperconjugated cation molecule complexes ( $\mathbf{L}$ and $\mathbf{K}$ ). The radical cation molecule and the hyperconjugate cation molecule complexes are appropriate to describe complexes involving open shell and closed shell cations, respectively. Such distinction is useful for modeling purposes in the future. Also, the step leading to the formation of a hyperconjugated cation molecule complex is a good alternative for a mechanistic step involving a 1,5-H rearrangement that is typically described as an even-electron McLafferty rearrangement.

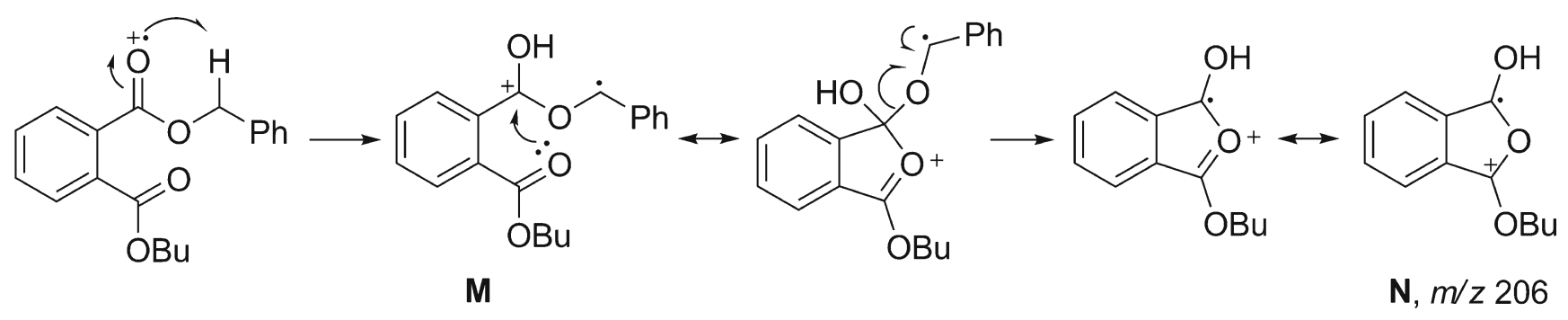

Scheme 2. Mechanism for the formation of $\mathrm{m} / \mathrm{z} 206$ 


\section{Acknowledgments}

The purchase of the GC-MSMS instrument was made possible by a grant from the United States Army Research Office. The authors acknowledge the United States Department of Energy for its continuous support for our environmental research and teaching laboratory, as well as the support from Spelman College's office of research resources.

\section{References}

1. Lovekamp-Swan, T., Davis, B.J.: Mechanisms of phthalate Ester toxicity in the female reproductive system. Environ. Health Perspect. 111, 139-45 (2003)

2. Yinon, J.: Mass spectral fragmentation pathways in phthalate Esters. A tandem mass spectrometric collision-induced dissociation study. Org. Mass Spectrom. 23, 755 (1988)

3. Yao, Z., Wen, H., Zha, Q., Zhao, S.: Intermolecular alkyl transfer reactions in the fast atom bombardment mass spectrometry of Esters. $J$. Mass Spectrom. 31, 955-960 (1996)

4. Stemmler, E.A., Diener, J.L., Swift, J.A.: Gas-phase reactions of O-.2 with alkyl and aryl Esters of benzenedicarboxylic acids. J. Am. Soc. Mass Spectrom 5, 990-1000 (1994)

5. Keki, S., Szilagyi, L.S., Deak, G., Zsuga, M.: Identification and fragmentation study of plasticizers with post-source decay matrixassisted laser desorption/ionization mass spectrometry. Rapid Commun. Mass Spectrom. 17, 783-787 (2003)

6. Jeilani, Y.J., Cardelino, B.H., Ibeanusi, V.M.: Positive chemical ionization triple-quadrupole mass spectrometry and ab initio computational studies of the multi-pathway fragmentation of phthalates. J. Mass Spectrom. 45, 678-685 (2010)

7. Harvan, D.J., Hass, J.R., Albro, P.W., Friesen, M.D.: Mass spectrometry of di-(2-Ethylhexyl)phthalate metabolites. Biol. Mass. Spectrom. 7, 242-246 (1980)

8. Flammang, R., Dechamps, N., Boulvin, M., Gerbaux, P., Nam, P.C., Nguyen, M.T.: On the loss of a methyl radical from metastable dimethyl terephthalate molecular ions. Int. J. Mass Spectrom. 261, 134 (2007)

9. Flammang, R., Dechamps, N., Boulvin, M., Gerbaux, P., Nam, P.C., Nguyen, M.T.: Unimolecular chemistry of metastable dimethyl isophthalate radical cations. Int. J. Mass Spectrom. 275, 110 (2008)

10. Frisch, M. J.; Trucks, G. W.; Schlegel, H. B.; Scuseria, G. E.; Robb, M. A.; Cheeseman, J. R.; Montgomery, J. A. Jr.; Vreven, T.; Kudin, K. N.; Burant, J. C.; Millam, J. M.; Iyengar, S. S.; Tomasi, J.; Barone, V.; Mennucci, B.; Cossi, M.; Scalmani, G.; Rega, N.; Petersson, G.A.; Nakatsuji, H.; Hada, M.; Ehara, M.; Toyota, K.; Fukuda, R.; Hasegawa, J.; Ishida, M.; Nakajima, T.; Honda, Y.; Kitao, O.; Nakai, H.; Klene, M.; Li, X.; Knox, J. E.; Hratchian, H. P.; Cross, J. B.; Bakken, V.; Adamo, C.; Jaramillo, J.; Gomperts, R.; Stratmann, R. E.; Yazyev, O.; Austin, A. J.; Cammi, R.; Pomeli, C.; Ochterski, J. W.; Ayala, P. Y.; Morokuma, K.; Voth, G. A.; Salvador, P.; Dannenberg, J. J.; Zakrzewski, V. G.; Dapprich, S.; Daniels, A. D.; Strain, M. C.; Farkas, O.; Malick, D. K.; Rabuck, A. D.; Raghavachari, K.; Foresman, J. B.; Ortiz, J.V.; Cui, Q.; Baboul, A. G.; Clifford, S.; Cioslowski, J.; Stefanov, B. B.; Liu, G.; Liashenko, A.; Piskorz, P.; Komaromi, I.; Martin, R. L.; Fox, D. J.; Keith, T.; Al-Laham, M. A.; Peng, C. Y.; Nanayakkara, A.; Challacombe, M.; Gill, P. M. W.; Johnson, B.; Chen, W.; Wong, M. W.; Gonzalez, C.; Pople, J. A. Gaussian 03, Revision C.02. Gaussian, Inc.: Wallingford CT, 2004.

11. Becke, D.: Density-functional exchange-energy approximation with correct asymptotic behavior. Phys. Rev. A 38, 3098-3100 (1988)

12. Lee, C., Yang, W., Parr, R.G.: Development of the colle-salvetti correlation-energy formula into a functional of the electron density. Phys. Rev. B 37, 785-789 (1988)

13. Hehre, W.J., Radom, L., Schleyer, P.V.R., Pople, J.A.: Ab Initio Molecular Orbital Theory. Wiley, New York (1986)

14. Reed, A.E., Weinstock, R.B., Weinhold, F.: Natural population analysis. J. Chem. Phys. 83, 735-746 (1985)
15. Glendening, E. D.; Reed, A. E.; Carpenter, J. E.; Weinhold, F. NBO Version 3.1.

16. Gonzalez, C., Schlegel, H.B.: An improved algorithm for reaction path following. J. Chem. Phys. 90, 2154-2161 (1989)

17. Gonzalez, C., Schlegel, H.B.: Reaction path following in mass-weighted internal coordinates. J. Phys. Chem. 94, 5523-5527 (1990)

18. GaussView 3.0 User's Reference. Gaussian, Inc.: Wallingford, CT, USA.

19. Leonid, S. Chemissian 1.771; 2005-2010. http://www.chemissian.com.

20. McLafferty, F.W., Turecek, F.: Interpretation of Mass Spectra, p. 81. University Science Books, Mill Valley, CA (1993)

21. Tu, Y.-P.: Dissociative protonation sites: reactive centers in protonated molecules leading to fragmentation in mass spectrometry. J. Org. Chem 71, 5482 (2006)

22. Tobitaa, S., Tajimab, S., Ishiharab, Y., Kojimab, M., Shigihara, A.: Single and double hydrogen atom migrations in substituted alkyl benzoates: a study on the substituent effect using mike spectrometry. Int. J. Mass Spectrom. Ion Processes 132, 129-136 (1994)

23. Zha, Q., Hayes, R.H., Nishimura, T., Meisels, G.G., Gross, M.L.: A study of the metastable dissociations of formate esters: a mclafferty rearrangement to a distonic radical cation. J. Phys. Chem. 94, 1286$1290(1990)$

24. McAdoo, D.J., Hudson, C.E., Skyiepa, M., Broido, E., Griffin, L.L.: Ion-neutral complexes as intermediates in the decompositions of $\mathrm{C}_{5} \mathrm{H}_{10} \mathrm{O}_{2}{ }^{-+}$isomers. J. Am. Chem. Soc. 109, 7648-7653 (1987)

25. Morton, T.H.: The reorientation criterion and positive ion-neutral complexes. Org. Mass Spectrom. 27, 353-368 (1992)

26. Jacoby, C.B., Gross, M.L., Zey, R.L.: The decompositions of $N$ (Substituted Benzalamino)Phthalimide radical cations embody ionneutral complexes and Stevenson's rule. J. Am. Soc. Mass Spectrom. 5, 837-844 (1994)

27. Stevenson, D.P.: Ionization and dissociation by electronic impact. the ionization potentials and energies of formation of sec-Propyl and tertButyl radicals. Some limitations on the method. Disc. Faraday Soc 10, 35-45 (1951)

28. Bernigaud, V., Drenck, K., Huber, B.A., Hvelplund, P., Jabot, T., Kadhane, U., Kirketerp, M.-B.S., Liu, B., Lykkegaard, M.K., Manil, B., Nielsen, S.B.: Electron-capture-induced dissociation of protoporphyrin IX ions. J. Am. Soc. Mass Spectrom 19, 809-813 (2008)

29. Hudson, C.E., McAdoo, D.J., Griffin, L.L.: Preference for an ionneutral complex-mediated pathway over a five-membered-ring $\mathrm{H}$ shift in the isomerization of $\mathrm{CH}_{3} \mathrm{O}^{+} \mathrm{HCH}_{2} \mathrm{CH}_{2}$ to $\mathrm{CH}_{3} \mathrm{CH}_{2} \mathrm{CH}_{2} \mathrm{OH}^{+}$by $\mathrm{Ab}$ initio theory. J. Am. Soc. Mass Spectrom 6, 1037-1046 (1995)

30. Smith, R.M.: Understanding Mass Spectra: A Basic Approach, pp. 234 236. Wiley, Hobonken, NJ (2004)

31. Tajima, S., Ishiguro, D., Mamada, M.: Unimolecular reactions of diethyl malonate cation in gas phase. J. Mass Spectrom. Soc. Jpn 52, 263-270 (2004)

32. Kingston, D.G.I., Bursey, J.T., Bursey, M.M.: Intramolecular hydrogen transfer in mass spectra. II. The McLafferty rearrangement and related reactions. Chem. Rev 74, 215-242 (1974)

33. Harvan, D.J., Hass, J.R., Albro, P.W., Friesen, M.D.: Mass spectrometry of di-(2-ethylhexyl)phthalate metabolites. Biol. Mass. Spectrom. 7, 242-246 (1980)

34. Gerbaux, P., Julien De Winter, J.D., Flammang, R., Nguyen, V.S., Nguyen, M.T.: Metastable dimethyl phthalate molecular ions: does the loss of a methoxyl radical proceed with or without a chimeric assistance? Int. J. Mass Spectrom 290, 127 (2010)

35. Siehl, H-U.; Walter, H. Conformational dependence of the $\beta$-deuterium equilibrium isotope effect in acyclic carbocations. Suppression of hyperconjugation by restricted rotation in the 2,4,4,6-tetramethylheptyl cation. J. Chem. Soc., Chem. Commun. 76-78 (1985).

36. Vrcek, I.V., Vrcek, V., Siehl, H.-U.: Quantum chemical study of degenerate hydride shifts in acyclic tertiary carbocations. J. Phys. Chem. A 106, 1604-1611 (2002)

37. Hunt, D.F., Shabanowitz, J., Harvey, T.M., Coates, M.: Scheme for the direct analysis of organics in the environment by tandem mass spectrometry. Anal. Chem. 57, 525-537 (1985)

38. NIST WebBook: http://webbook.nist.gov, date accessed 6-21-2010.

39. Dechamps, N., Flammang, R., Gerbaux, P.: Decarboxylation of metastable methyl benzoate molecular ions. J. Am. Soc. Mass Spectrom. 17, 807-814 (2006) 